\title{
Sequential Effects of Acute Meconium Obstruction on Pulmonary Function
}

\author{
NGHIA TRAN, CORINNE LOWE, EMIDIO M. SIVIERI, AND THOMAS H. SHAFFER \\ Departments of Physiology and Neonatology, School of Medicine, Temple University Health Sciences Center, \\ Philadelphia, Pennsylvania, USA
}

\begin{abstract}
Summary
The relationship between pulmonary function and the migration of meconium to distal airways was determined in 10 rabbits (mean weight $2.6 \mathrm{~kg}$ ) after insufflation of a meconium-saline mixture (1$2 \mathrm{ml} / \mathrm{kg}$ ). Animals were anesthetized, cannulated, intubated, and mechanically ventilated with $100 \%$ oxygen. Lung mechanical dysfunction was most severe during the early phase of meconium migration, 15 min postinsufflation. Substantial increases in inspiratory lung resistance $\left(R_{I}\right)$ and expiratory lung resistance $\left(R_{E}\right)$ suggest that the site of obstruction at $15 \mathrm{~min}$ was the large airways. A decrease in dynamic lung compliance with unchanged static compliance characterizes the obstruction as partial. At $\mathbf{1 5}$ min and throughout the migration process, $\mathbf{R}_{\mathrm{E}}$ was greater than $\mathbf{R}_{\mathrm{I}}$, demonstrating a check-valve effect. This phenomenon was substantiated by an increased functional residual capacity (FRC) in all rabbits, presumably due to gas trapping. Secondary to these changes, marked hypoxemia, hypercapnea, and acidosis developed in spite of assisted ventilation with $100 \%$ oxygen. At 60 and 120 min postinsufflation, both $R_{I}$ and $R_{E}$ decreased as compared to 15 min. This suggests that the predominant site of obstruction shifted to medium and small airways concomitant with the migration of meconium. Widespread and uneven distribution of meconium still produced significant frequency dependence of lung compliance. Static compliance remained unchanged, indicating that meconium does not affect surface-active or tissue properties of the lung within $120 \mathrm{~min}$ postinsufflation. These data suggest that effective respiratory management after meconium aspiration is dependent on the degree of meconium migration, as reflected by pulmonary mechanics.
\end{abstract}

\section{Speculation}

Significant effects of meconium aspiration on lung function are attributable to migrating obstructive phenomena, which result in a more severe lung dysfunction in earlier stages postinsufflation of meconium than in progressively later stages. It is appealing to speculate that noninvasive pulmonary function measurements made in newborn infants may quantitate the degree of mechanical obstruction and meconium migration in the airways. This information would provide guidelines for effective respiratory management of infants with meconium aspiration syndrome (MAS). Based on the present animal model, elevated oxygen therapy should be employed early to offset the severe hypoxemia. In addition, the check-valve effect $\left(R_{E}>R_{I}\right)$ indicates the use of a low I/E ratio in assisted ventilation. It has been shown that continuous positive airway pressure improves arterial oxygen tension in some newborns with MAS. However, in light of the mechanical dysfunction resulting in an increased $F R C$, caution is recommended in the use of end distending pressure within $2 \mathrm{hr}$ after meconium aspiration.

The aspiration of meconium in the perinatal period has been shown to produce various degrees of respiratory distress. To date, chemical, histologic, and roentgenographic investigations regard- ing the pathologic process of meconium aspiration have been conducted $(1,10,11,19,21,22)$. Results have shown that whereas the irritating action of meconium on the pulmonary parenchyma might initiate a chemical or bacterial pneumonitis $(4,21)$, the importance of inflammation with regard to severe respiratory dysfunction may not be great (11). Rather, mechanical airway obstruction by particles of meconium has been shown to play the most important role in the early pathophysiology of MAS (21).

Evidence for obstruction and migration of meconium has been supported by roentgenographic methods, where Gooding et al. (10) demonstrated that tantalum-labeled meconium was cleared from the trachea and mainstem bronchi within $1 \mathrm{hr}$ and migrated progressively into the lung periphery with breathing. Whereas physiologic effects of obstruction on lung function have been studied $(2,8,12,15,24)$, little data are available on pulmonary mechanics in animals or infants with acute meconium obstruction. Because of the migration properties of meconium, the physiologic response of obstructive phenomena in general cannot be extrapolated to the pathophysiology of pulmonary function in meconium aspiration. The purpose of this study is to determine the sequential physiologic effects of acute meconium obstruction on pulmonary function as they vary with the migration of meconium to the distal airways. Such data will provide further insight into the pathophysiology and respiratory management of infants with MAS.

\section{MATERIALS AND METHODS}

Sixteen young adult rabbits having a mean body weight of 2.6 $\mathrm{kg}$ (range $1.8-3.1 \mathrm{~kg}$ ) were studied. Anesthesia (ip) was induced with sodium pentobarbital $(30 \mathrm{mg} / \mathrm{kg}$ ) and supplementary doses were given as needed. After the animal was secured in the supine position, an endotracheal tube (Air Shields, $4 \mathrm{~mm}$ ID) was inserted through a tracheostomy with its tip proximal to the carina. The carotid artery was catheterized to a depth of 5-8 cm with a French no. 3.5 polyvinyl chloride catheter. Succinylcholine chloride (Anectine $2 \mathrm{mg} / \mathrm{kg}$ ) was administered iv. Supplementary doses were required at one-half $\mathrm{hr}$ intervals. The tracheal tube was connected to a volume controlled piston pump (Harvard small animal respirator). Tidal volume and pump frequency were adjusted to maintain an arterial carbon dioxide tension and $\mathrm{pH}$ with the range of spontaneous breathing values, and, thereafter, remained constant through the experiments. The inspired oxygen concentration was maintained at $100 \%$ throughout the experiment. Once arterial blood gases were stabilized, repeated measurements of pulmonary mechanics were made during a 30 - to 60 -min period to establish a baseline control.

Meconium was collected from a healthy newborn, and a $25 \%$ meconium-75\% saline mixture $(1-2 \mathrm{ml} / \mathrm{kg}$; $\mathrm{pH}=7.0)$ was insufflated twice with a 5 -min interval through the endotracheal tube. Pulmonary mechanics, arterial blood gases, and $\mathrm{pH}$ were measured at 15, 60, and 120 min postinsufflation. Animals were killed and gross lung sections were examined postmortem for meconium. Statistical differences in arterial blood gases and pulmonary mechanics pre- and postinsufflation were evaluated by the paired Student's $t$ test. 
Arterial blood gas tensions $\left(\mathrm{PaO}_{2}\right.$ and $\left.\mathrm{PaCO}_{2}\right)$ and $\mathrm{pH}$ were determined on $1 \mathrm{ml}$ samples drawn from the carotid artery after $2 \mathrm{ml}$ had been withdrawn to clear out the catheter. These $2 \mathrm{ml}$ were reinfused followed by $1 \mathrm{ml}$ of heparinized saline solution. Analysis was conducted using a Radiometer amplifier and cuvettes with membrane covered oxygen and carbon dioxide electrodes, and a capillary glass electrode for $\mathrm{pH}$.

Mechanics of breathing were studied by simultaneously monitoring transpulmonary pressure, inspiratory and expiratory flow rates, and tidal volume on a polygraph recorder (Grass Model 7) and a vector scope (Electronics for Medicine, DR-8). Intraesophageal pressure was measured with an esophageal balloon $2.5 \mathrm{~cm}$ in length and $3.0 \mathrm{~mm}$ in diameter. After the balloon was filled with $0.5 \mathrm{ml}$ of air, it was positioned in approximately the lower third of the esophagus. The esophageal catheter was protected at the mouth with a polyvinyl 200 tube. As shown in Figure 1, the esophageal catheter was connected to one side of a Statham PM 131 TC differential strain gauge transducer with a low volume adapter inserted at the inlet. The tracheal pressure was transmitted by connecting the other side of the same transducer gauge to the side tap of the tracheal tube. The recorded signal represented an estimate of transpulmonary pressure. Air flow was measured with a Fleisch \#0 pneumotachograph connected to a Statham PM 283 TC differential strain gauge pressure transducer of low volume displacement. Tidal volume was determined by electronic integration of the signal from the pneumotachograph. The transducer, pneumotachograph, and esophageal balloon system were tested for transient response and did not introduce phase lag or damping in the frequency range encountered $(0.1-4.0 \mathrm{~Hz})$.

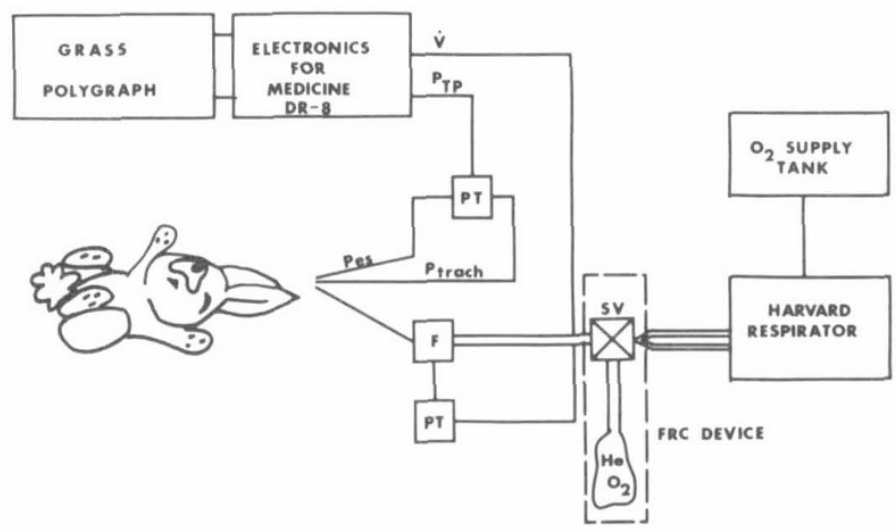

Fig. 1. Schematic of experimental apparatus. Key: $P T=$ pressure transducer; $F=$ pneumatachograph; $P_{e s}=$ esophageal pressure; $P_{\text {trach }}=$ tracheal pressure; $\dot{V}=$ air flow; $S V=$ solenoid valve.
FRC was determined by a modified closed-circuit helium dilution technique $(14,21)$. An electrically operated fast closing valve (closure time within $3 \mathrm{msec}$ ) sequenced by a relay was used. When the valve was energized, the endotracheal tube connection was switched from the mechanical ventilator to a rebreathing bag operated manually. Dead space of the system, including the endotracheal tube and valve was $8.4 \mathrm{ml}$.

Values of respiratory rate were ascertained directly from the polygraph record and lung compliance was determined graphically by the method of Neergaard and Wirz (17). Lung resistance was computed by dividing the difference in transpulmonary pressure at midvolume points during inspiration and expiration by the algebraic difference in airflow at those instants. Each resistance and compliance determination was based on the average of at least three breaths. Measurements of dynamic lung compliance and resistance were also made on the vector scope (16). Instrument calibrations were adjusted such that the slope of the pressure-flow or pressure-volume curves could be read between 10.5-78.5 degrees. It was found that the measurement error in determining lung compliance or resistance is less than $10 \%$ provided the slope falls within this range (13). A constant tidal volume and frequency history preceded all measurements. Dynamic compliance was calculated and averaged over five breaths using the vector scope method as described above. Quasi-static pressure-volume measurements above FRC were made during both inflation and deflation at 15 and 120 min postinsufflation of meconium. The change in transpulmonary pressure was measured on the polygraph recorder during constant flow infusion and withdrawal of $80 \mathrm{ml}$ of air in $20 \mathrm{ml}$ increments. Due to the time limitations associated with an in vivo preparation, a maximum of $20 \mathrm{sec}$ was permitted for pressure equilibration at each lung volume. The pneumotachograph was placed in the ventilatory circuit only during the pulmonary mechanics measurements to minimize dead space.

\section{RESULTS}

Of the 16 rabbits studied, seven died after insufflation of meconium, six of which did so before measurements were obtained. Table 1 summarizes weight, pulmonary mechanics, and blood gas control values for 10 rabbits. Values for individual animals are presented along with group mean values \pm SEM. As shown, the SEM in lung mechanics and arterial blood gases demonstrates a small variation among the animals.

Ventilation was achieved with a tidal volume ranging from 25$30 \mathrm{ml}$ and respiratory rates from $25-30$ breaths/min. Mean SEM values of $\mathrm{PaO}_{2}, \mathrm{PaCO}_{2}$, and $\mathrm{pH}$ at $\mathrm{FIO}_{2}=1.0$ and constant ventilation history are presented before (control) and 15, 60, and $120 \mathrm{~min}$ after insufflation of meconium in Figure 2. As expected,

Table 1. Summary of weight, lung mechanics, and blood gas control data for 10 rabbits

Pulmonary function

\begin{tabular}{|c|c|c|c|c|c|c|c|c|c|}
\hline \multirow[b]{3}{*}{ Rabbit } & \multirow[b]{3}{*}{ Weight (kg) } & \multicolumn{8}{|c|}{ Pulmonary function } \\
\hline & & \multirow[b]{2}{*}{$\mathrm{FRC}(\mathrm{ml} / \mathrm{kg})$} & \multirow{2}{*}{$\begin{array}{l}\text { Dynamic compli- } \\
\text { ance }\left(\mathrm{ml} / \mathrm{cm} \mathrm{H} \mathrm{H}_{2} \mathrm{O} /\right. \\
\mathrm{kg})\end{array}$} & \multirow[b]{2}{*}{$\begin{array}{l}\text { Specific compli- } \\
\text { ance }\left(1 / \mathrm{cm} \mathrm{H} \mathrm{H}_{2} \mathrm{O}\right)\end{array}$} & \multicolumn{2}{|c|}{$\begin{array}{c}\text { Resistance } \\
\text { (cm H} \mathrm{H}_{2} \mathrm{O} \cdot \mathrm{sec} / \mathrm{liter} / \mathrm{kg} \text { ) }\end{array}$} & \multicolumn{3}{|c|}{ Arterial Blood Gas } \\
\hline & & & & & Inspiratory & Expiratory & $\begin{array}{l}\mathrm{PaO}_{2}(\mathrm{~mm} \\
\mathrm{Hg})\end{array}$ & $\begin{array}{c}\mathrm{PaCO}_{2}(\mathrm{~mm} \\
\mathrm{Hg})\end{array}$ & $\mathrm{pH}$ \\
\hline 7116 & 2.9 & & 1.55 & & 2.4 & 10.1 & 460 & 42 & 7.41 \\
\hline 7117 & 2.5 & 31.2 & 2.33 & 0.075 & 15.7 & 19.2 & 500 & 32 & 7.37 \\
\hline 7128 & 3.0 & 39.2 & 2.13 & 0.054 & 4.1 & 18.2 & 465 & 44 & 7.42 \\
\hline 7129 & 2.8 & 33.6 & 0.97 & 0.029 & 7.9 & 9.5 & 530 & 47 & 7.30 \\
\hline 71210 & 2.5 & 35.6 & 0.75 & 0.021 & 13.7 & 33.3 & 525 & 47 & 7.45 \\
\hline 71211 & 2.8 & 26.5 & 0.84 & 0.032 & 12.3 & 18.5 & 470 & 44 & 7.39 \\
\hline 71212 & 2.2 & 33.4 & 1.26 & 0.038 & 28.3 & 18.0 & 525 & 37 & 7.25 \\
\hline 8113 & 2.5 & 27.4 & 1.37 & 0.050 & 17.6 & 15.1 & 500 & 34 & 7.14 \\
\hline 8114 & 2.8 & 51.6 & 2.00 & 0.039 & 14.2 & 10.6 & 470 & 43 & 7.31 \\
\hline 8116 & 1.8 & 60.6 & 1.64 & 0.027 & 33.2 & 20.4 & 530 & 42 & 7.28 \\
\hline Mean & 2.5 & 37.7 & 1.48 & 0.041 & 14.9 & 17.3 & 497 & 40 & 7.33 \\
\hline SEM & 0.04 & 3.8 & 0.17 & 0.006 & 3.1 & 2.2 & 9 & 2 & 0.030 \\
\hline
\end{tabular}



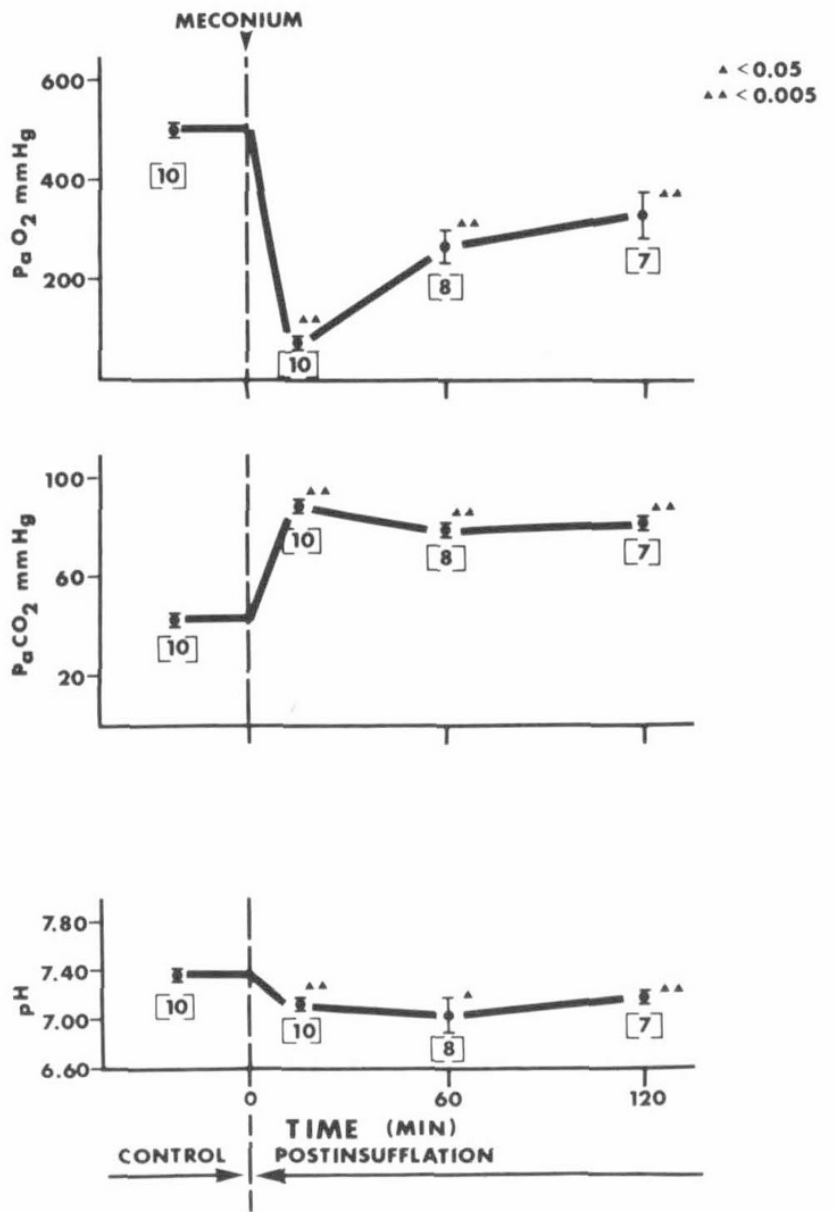

Fig. 2. Group mean values $\pm \mathrm{SEM}$ for $\mathrm{PaO}_{2}, \mathrm{PaCO}_{2}$, and $\mathrm{pH}$ before and after meconium insufflation.

all animals displayed severe hypoxemia $\left(\mathrm{PaO}_{2}=65 \pm 6 \mathrm{SEM} \mathrm{mm}\right.$ $\mathrm{Hg} ; P<0.005)$ at $15 \mathrm{~min}$ postinsufflation as compared to the control $\left(\mathrm{PaO}_{2}=497 \pm 9\right.$ SEM mm Hg$)$. At 60 and $120 \mathrm{~min}$, an increasing trend of $\mathrm{PaO}_{2}$ was observed; however, $\mathrm{PaO}_{2}$ remained significantly below the control level. As shown in Figure 2, all animals demonstrated persistent $\mathrm{CO}_{2}$ retension and respiratory acidosis for $2 \mathrm{hr}$ after meconium insufflation.

Alterations in dynamic lung compliance $\left(\mathrm{C}_{\mathrm{L}}\right)$, specific lung compliance, and FRC after meconium insufflátion are illustrated in Figure 3. As shown at $15 \mathrm{~min}, \mathrm{C}_{\mathrm{L}}=0.43 \pm 0.07 \mathrm{SEM} \mathrm{ml} / \mathrm{cm}$ $\mathrm{H}_{2} \mathrm{O} / \mathrm{kg}$ was $34 \%$ of control and remained significantly lower through 120 min postinsufflation. Likewise, specific lung compliance remained significantly decreased $(P<0.005)$ from the control level. FRC increased $37 \%(P<0.005)$ at $15 \mathrm{~min}$ postinsufflation, progressively increasing to a maximum value $(F R C=68.3 \pm 11.1$ $\mathrm{SEM} \mathrm{ml} / \mathrm{kg})$ at $2 \mathrm{hr}$ as compared to the control level $(37.7 \pm 3.8$ $\mathrm{SEM} \mathrm{ml} / \mathrm{kg}$ ).

A comparison of typical quasi-static pressure-volume (P-V) curves at 15 and 120 min postinsufflation is presented in Figure 4. In the upper panel, at $15 \mathrm{~min}$ postinsufflation, values for static compliance (slope of the deflation limb) were the same as control. As shown, the slope of the inflation limb was decreased, indicating incomplete pressure equilibration at each lung volume. At 120 min, the slope of the quasi-static pressure-volume curve was virtually identical to that of the control curve, demonstrating that the static compliance remained unchanged. Furthermore, the increase in the slope of the inflation limb towards control suggests more complete pressure equilibration at this time.

Figure 5 shows the mean \pm SEM changes in $R_{I}$ and $R_{E}$ before and after meconium was insufflated. $R_{E}$ was significantly greater $(P<0.005)$ than control at all times postinsufflation, and a maximum response was observed at $15 \mathrm{~min}\left(\mathrm{R}_{\mathrm{E}}=76.0 \pm 9.9 \mathrm{SEM}\right.$ $\left.\mathrm{cm} \mathrm{H}_{2} \mathrm{O} \cdot \mathrm{sec} / \mathrm{liter} / \mathrm{kg}\right) . \mathrm{R}_{\mathrm{I}}$, however, was greater $(P<0.05)$ than
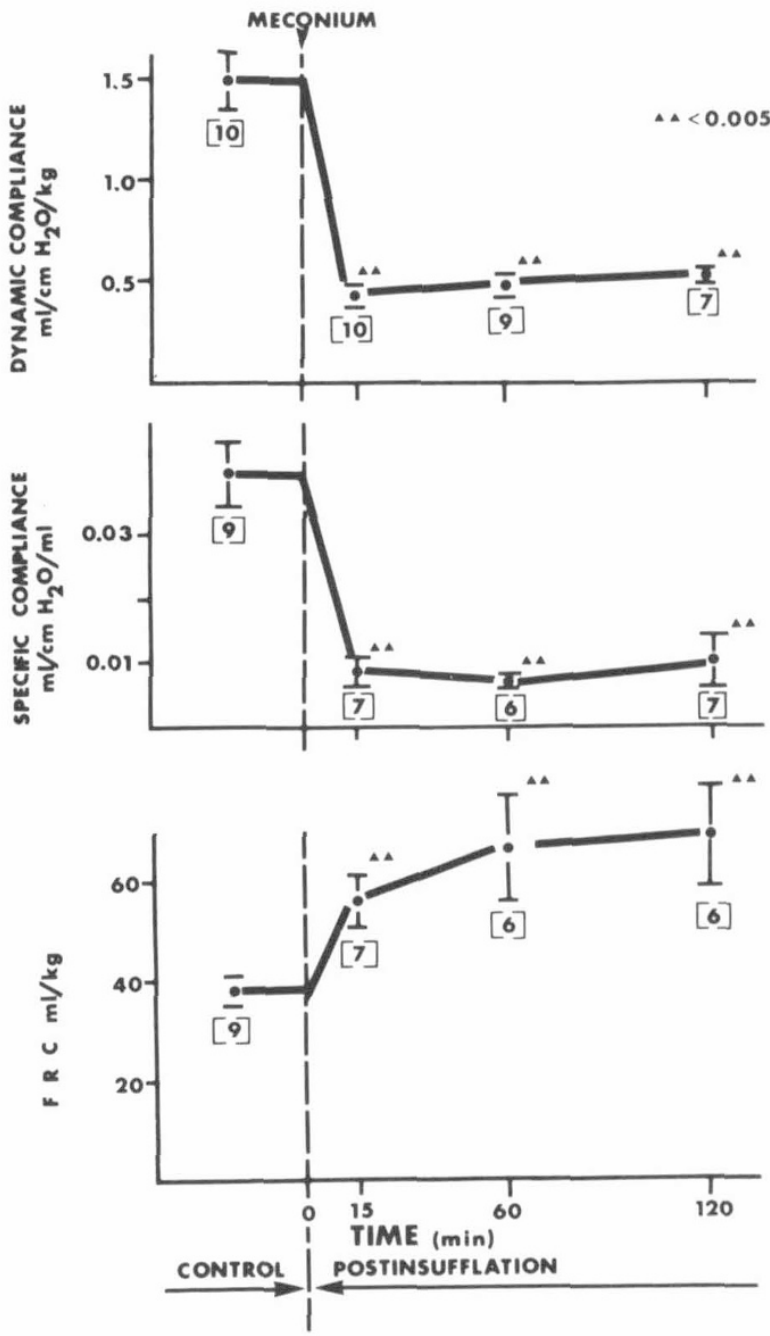

Fig. 3. Group mean values \pm SEM for dynamic lung compliance, specific lung compliance, and FRC before and after meconium insufflation.

control only at $60 \mathrm{~min}$, and at all times postinsufflation less $(P<$ 0.005 ) than $R_{E}$. Inspection suggests that postinsufflation changes in $R_{I}$ closely paralleled changes in $R_{E}$ with time; however, no statistical correlation was found since variation in resistance values among the animals was great.

Postmortem gross examination revealed meconium throughout the large and small airways, as far distal as $0.2 \mathrm{~mm}$ segments for all rabbits. It is noteworthy that this observation includes one rabbit who died $20 \mathrm{~min}$ after meconium insufflation. All lungs appeared friable and hemorrhagic, and blebs were found in the lungs of two rabbits. At $2 \mathrm{hr}$, no evidence of pneumothorax was observed, and only one rabbit appeared to have lobar atelectasis.

\section{DISCUSSION}

This study demonstrates sequential alterations in pulmonary function in rabbits after insufflation of a meconium-saline mixture. These functional changes in lung mechanics quantitate the previous roentgenographic observations of meconium migration to peripheral airways in infants (19) and experimental models (10).

In all rabbits studied, lung dysfunction was most severe during the early phase of meconium migration, 15 min postinsufflation. Meconium induced obstruction was evidenced primarily by the large increase in $R_{I}(266 \%)$ and $R_{E}(431 \%)$. As previously demonstrated in airway obstruction models using beads (2), these substantial increases in lung resistance suggest that the site of obstruction is the large airways. This does not rule out the possi- 
15 MIN POSTINSUFFLATION

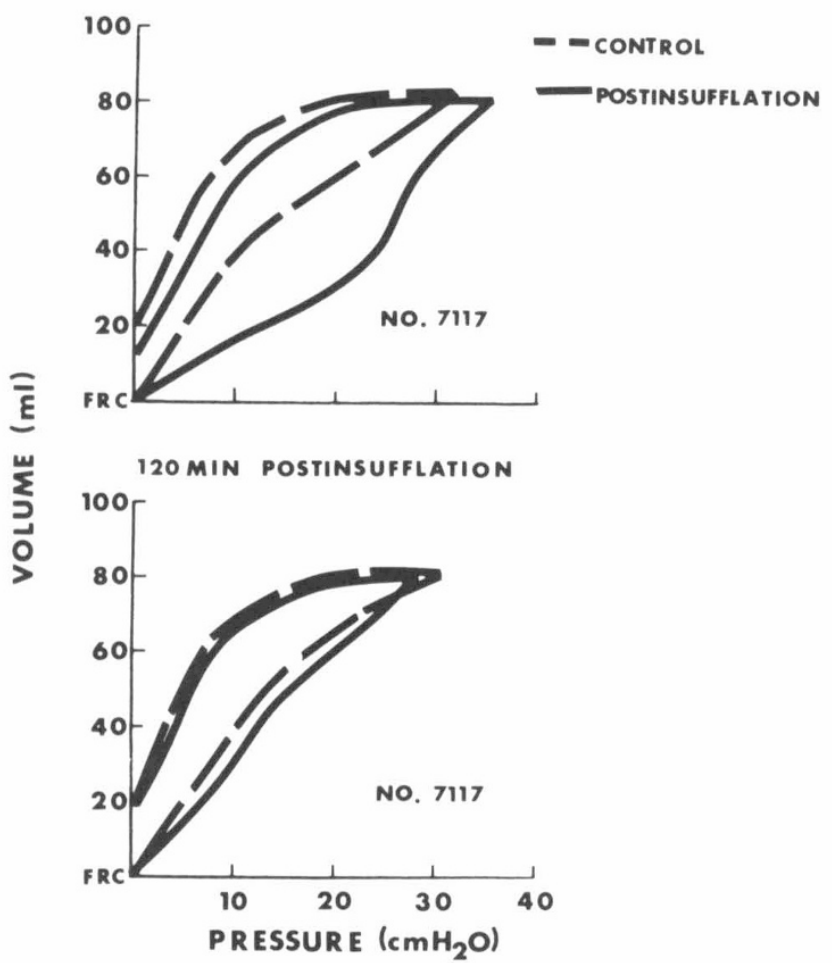

Fig. 4. A comparison of typical quasi-static pressure-volume curves at 15 and $120 \mathrm{~min}$ postinsufflation of meconium.

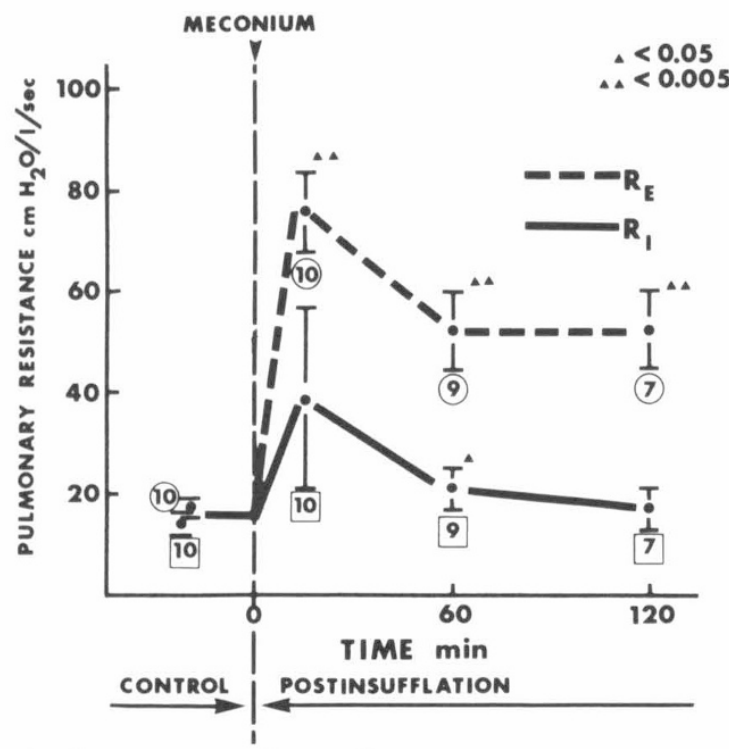

Fig. 5. Group mean values $\pm S E M$ for $R_{I}$ and $R_{E}$ before and after meconium insufflation.

bility of significant obstruction in the small airways at this early time interval. Because peripheral airway resistance is only a small part of total lung resistance, even considerable obstruction in these areas would have little effect on $R_{I}$ and $R_{E}$. The obstruction as observed by physiologic alterations in pulmonary resistance indicates the existence of physical obstruction; however, it is also possible that these alterations include a reactive component of the airways to meconium. In addition, the experimental data of this study are consistent with those of Gooding et al. (10) who, at postmortem, noted tenacious meconium plugs in the trachea and mainstem bronchi of newborn puppies which had succumbed rapidly to meconium aspiration.

At $15 \mathrm{~min}$ and throughout the migration process, $R_{E}$ was greater than $R_{I}$ demonstrating a check-valve (ball-valve) effect. As the airway expands during inspiration, air passes around the meconium plugs and enters the alveoli. However, as the airway collapses around the obstruction during expiration, air remains trapped distally. The observed increase in FRC in rabbits, presumably due to gas trapping, further substantiates a check-valve phenomenon. This increased FRC is in agreement with the experimental findings of Tyler et al. (22). Clinically, radiographic findings of a characteristic hyperexpanded chest with flattening of the diaphragm (19, 23) and histologic evidence of emphysema (1) also support the suggestion that trapping occurs in MAS.

Dynamic lung compliance decreased to $34 \%$ of control value, and showed little improvement throughout the experiment. Because migration to the alveoli is unlikely within $15 \mathrm{~min}$ and static compliance did not change, surface or tissue alterations probably do not contribute to this decrease. More likely, the unequal obstruction of larger airways results in frequency dependence of compliance and substantial decreases in $\mathrm{C}_{\mathrm{L}}$ at breathing rates as low as $20-30$ breaths/min (2). It is also possible that with gas trapping and hyperinflation of alveoli, individual units become stiffer, resulting in a decreased $\mathrm{C}_{\mathrm{L}}$.

If large airways were completely occluded by meconium, one might expect that static compliance would decrease, but that $\mathrm{C}_{\mathrm{L}}$ would be unaffected. However, if the occlusion were partial and randomly distributed, static compliance would remain unchanged, whereas $C_{L}$ would decrease. Because the data from the ten surviving rabbits are characterized by the latter description (Figs. 3 and 4), partial obstruction of the large airways is a likely explanation for the observed changes in lung mechanics during the early stages of meconium migration. Secondary to these changes, marked hypoxemia, hypercapnea, and acidosis (Fig. 2) developed in spite of assisted ventilation with $100 \%$ oxygen. Clinically, gas exchange and acid-base problems are common findings in symptomatic newborns with meconium-stained amniotic fluid $(1,23)$. The seven rabbits who succumbed most probably suffered anoxia secondary to complete obstruction of the large airways. Both incomplete and complete obstruction patterns have been characterized in newborns with MAS (23).

At 60 and 120 min postinsufflation of meconium, both $R_{I}$ and $R_{E}$ decreased as compared to $15 \mathrm{~min}$. This suggests that the predominant site of obstruction shifted to the medium and small airways, concomitant with the migration of meconium with time. Although the obstructive effects of meconium in the smaller airways were less profound with respect to $R_{I}$ and quasi-static pressure-volume properties, widespread and uneven distribution of meconium still produced significant frequency dependence of $\mathrm{C}_{\mathrm{L}}$ (34\% of control). Static compliance did not change throughout the experiment indicating that meconium does not affect surfaceactive or tissue properties of the lung within $2 \mathrm{hr}$ of aspiration.

Typically, it has been shown that the amount, particle size, and consistency of the meconium aspirated, and the length of time over which meconium is in the airways greatly differ among MAS newborns, and produce various degrees of pulmonary dysfunction (1). By insufflating a standardized homogeneous solution in a predetermined constant dosage per $\mathrm{kg}$, variation was reduced enabling the comparison of obstructive effects of meconium on pulmonary mechanics as they vary with time. The possibility of chemical and bacterial effects, which have been shown to be insignificant within $6-10 \mathrm{hr}$ after aspiration of meconium $(11,22)$ were eliminated by conducting the study over a 2 -hr period. Further complications of pneumonitis due to the hyperosmolarity and alkalinity of amniotic fluid were reduced by insufflating meconium in an isotonic saline solution. Saline aspiration in itself has been shown to cause little damage (5). To simplify the complex newborn situation of transitional circulations and general pulmonary instability, adult animals were chosen. Generally, MAS newborns are term or postterm and have fully developed lungs comparable to the adult rabbit in dimension, weight, and volume. Therefore, the sequence of obstructive events elicited in this model may closely reflect that of the human newborn. In addition, the adult model has been used previously rather than the newborn to investigate the effects of meconium aspiration (22). 
Certain other causes of experimental variability were excluded with reasonable certainty. A change in the location of the esophageal balloon between measurements was unlikely because the balloon was secured with tape to prevent its movement during the course of the experiment. Instrument calibrations, pneumotachograph adaptors, and tracheal cannula position all remained constant throughout the individual experiments. Before pulmonary function measurements, the tidal volume and breathing frequency were maintained constant to prevent alterations in lung volume which might otherwise have produced changes in lung mechanics. Also, the transducer and esophageal balloon were tested dynamically and found to be responsive in the frequency range of $0.1-4.0$ $\mathrm{Hz}$. Control lung compliance and resistance data presented herein are consistent with those in the literature for rabbits $(3,6)$.

In conclusion, this study demonstrates that there are rapid sequential alterations in lung mechanics after the insufflation of a meconium-saline mixture. These functional changes in mechanical properties as a result of obstruction quantitate the migration of meconium from large to small airways. In light of these changes, it is suggested that effective respiratory management after meconium aspiration is dependent on the degree of meconium migration. Guidelines for effective respiratory management would include early employment of elevated oxygen therapy to offset severe hypoxemia. The check-valve effect $\left(R_{E}>R_{I}\right)$ indicates the use of a low $\mathrm{I} / \mathrm{E}$ ratio in assisted ventilation. In light of the mechanical dysfunction resulting in an increased FRC, caution is recommended in the use of positive end-expiratory pressure (9) within $2 \mathrm{hr}$ after meconium aspiration.

\section{REFERENCES AND NOTES}

1. Bacsik, R. C.: Meconium aspiration syndrome. Ped. Clin. N. Am., 24: 463 (1977).

2. Brown, R., Woolcock, A. J., Vincent, N. J., and Macklem, P. T.: Physiological effects of experimental airway obstruction with beads. J. Appl. Physiol., 27: 328 (1969).

3. Caldwell, E. J., and Fry, D. L.: Pulmonary mechanics in the rabbit. J. Appl. Physiol., 27: 280 (1969).

4. Cruichshank, A. H.: The effects of the introduction of amniotic fluid into rabbits' lungs. J. Pathol. Bacteriol., 61: 527 (1949).

5. Davidson, J. T., Rubin, S., Eyal, Z.: A comparison of the pulmonary response to the endotracheal instillation of $0.1 \mathrm{~N}$ hydrochloric acid and Hartmann's solution in the rabbit. Br. J. Anesth., 46: 127 (1974).

6. Davidson, J. T., Wasserman, K., Lillington, G. A., and Schmidt, R. W.: Effect of aging on respiratory mechanics and gas exchange in rabbits. J. Appl. Physiol., 21: 837 (1966).
7. Fenton, A. N., and Steer, C. M.: Fetal distress. Am. J. Obstet. Gynecol., 83: 354 (1962).

8. Finucane, K. E., and Colebatch, H. J. H.: Elastic behavior of the lung in patients with airway obstruction. J. Appl. Physiol., 26: 335 (1969).

9. Fox, W. W., Berman, L. S., Downes, J. J., and Peckham, G. J.: The therapeutic application of end-expiratory pressure in the meconium aspiration syndrome. Pediatrics, 56: 214 (1975).

10. Gooding, C. A., Gregory, G. A., Taber, P., and Wright, R. R.: An experimental model for the study of meconium aspiration of the newborn. Radiology, 100: 137 (1971).

11. Goodlin, R. C.: Meconium aspiration. Obstet. Gynecol., 32: 94 (1968).

12. Grimby, G., Takishima, T., Graham, W., Macklem, P., and Mead, J.: Frequency dependence of flow resistance in patients with obstructive lung disease. J. Clin. Invest., 47: 1455 (1968).

13. Koen, P. A., Moskowitz, G. D., and Shaffer, T. H.: Error analysis for vector scope measurement of pulmonary mechanics. IEEE Trans. Biomed. Eng., 25: 204 (1978)

14. Koen, P. A., Moskowitz, G. D., and Shaffer, T. H.: Instrumentation for measuring functional residual capacity in small animals. J. Appl. Physiol., 43: 755 (1977)

15. Macklem, P. T., Frasier, R. C., and Bates, D. V.: Bronchial pressures and dimensions in health and obstructive airway disease. J. Appl. Physiol., 18: 699 (1963).

16. Mead, J., and Whittenberger, J. L.: Physical properties of human lungs measured during spontaneous respiration. J. Appl. Physiol., 5: 779 (1953).

17. Neergaard, K., and Wirz, K.: Uber eine methode zur messung der lung-enelastizitat am lebenden menschen, insbesondere beim emphysem. Z. Klin. Med.. 105: 35 (1927).

18. Otis, A. B., McKerrow, C. B., Barlett, R. A., Mead, J., McIlroy, M. A., Silverstone, N. J., and Radford, E. P.: Mechanical factors in distribution of pulmonary ventilation. J. Appl. Physiol., 8: 427 (1956).

19. Peterson, H. G., and Pendleton, M. E.: Contrasting roentgenographic pulmonary patterns of the hyaline membrane and fetal aspiration syndrome. Am. J. Roentgenol., 74: 800 (1955).

20. Saunders, R. A., and Milner, A. D.: Pulmonary pressure/volume relationships during the last phase of delivery and the first postnatal breaths in human subjects. J. Pediatr., 93: 667 (1978).

21. Schwartz, J. G., Fox, W. W., and Shaffer, T. H.: A method for measuring functional residual capacity (FRC) in neonates with endotracheal tubes. IEEE Trans. Biomed. Eng., 25: 304 (1978).

22. Tyler, D. C., Murphy, J., Cheney, F. W.: Mechanical and chemical damage to lung tissue caused by meconium aspiration. Pediatrics, 62: 454 (1978).

23. Vidyasagar, D., Yeh, T. F., Harris, V., and Pildes, R. S.: Assisted ventilation in infants with meconium aspiration syndrome. Pediatrics, 56: 208 (1975).

24. Woolcock, A. J., Vincent, N. J., and Macklem, P. T.: Frequency dependence of compliance as a test for obstruction in small airways. J. Clin. Invest., 48: 1097 (1969).

25. The authors thank Ms. Ethel Lidman for her technical assistance.

26. This research was supported by Public Health Service Grant HL 22843.

27. Requests for reprints should be addressed to: Thomas H. Shaffer, Ph. D., Temple University School of Medicine, Department of Physiology, 3420 North Broad Street, Philadelphia, Pennsylvania 19140, USA

28. Received for publication November 20, 1978

29. Accepted for publication February 1, 1979. 